\title{
Risks for non-communicable chronic diseases: A cross-sectional study with undergraduate nursing students
}

\author{
Hérica Cristina Alves de Vasconcelos, Niciane Bandeira Pessoa Marinho , Roberto Wagner J únior \\ Freire de Freitas , Lorena Barbosa Ximenes, Ana Karina Bezerra Pinheiro, Marta Maria Coelho \\ Damasceno
}

Nursing Department, Federal University of Ceará, Brazil

Correspondence: Hérica Cristina Alves de Vasconcelos. Address: Zuca Accioly street, 633 apt $201 \mathrm{H}$ Dunes. CEP: 60191-335 Fortaleza, Ceara, Brazil. Telephone: 55-858-834-9158. E-mail: hekinha@hotmail.com

Received: December 29, 2011

Accepted: January 30, $2012 \quad$ Published: August 1, 2012

DOI : $10.5430 /$ jnep.v2n3p103

URL: http://dx.doi.org/10.5430/jnep.v2n3p103

\section{Abstract}

Background: The situational analysis is one of the essential competencies of the nurse as a health promoter to ensure planning by the use of adequate strategies, coherent approaches and attainable goals in a community. The present study focused on performing a situational analysis of lifestyles related to the risk factors for non-communicable chronic diseases (NCCD) with undergraduate nursing students.

Methods: A cross-sectional study developed with 77 female nursing undergraduates where the sociodemographic variables, physical conditions and lifestyles inherent to the risk for non-communicable chronic diseases were investigated.

Results: Female undergraduates between the ages of 20 and 24 years prevailed in the study. They were white, single, belonged to social class B and were in the 3rd and 4th year of the course. Though sedentary, the students had their weight fitting their height and their waist circumference values within normal standards. In addition to this, they stated being non-smokers, besides presenting low risk regarding alcohol consumption.

Conclusions: It is worth noting the nurse's role as a health promoter at the development of encouragement strategies for healthy life practices and the planning of interventions against sedentarism.

\section{Key words}

Chronic diseases, Health promotion, Nursing

\section{I ntroduction}

The nurse as a health promoter is defined as a professional specialized in maintaining and improving the populations' health by acting in the reduction of inequalities among populational groups through the joint action plans in the Ottawa letter ${ }^{[1]}$. Some health promotion competencies are necessary for this professional, so that his/her activities can become efficiently and effectively operational. Such competencies represent a common base for all the health promoters' roles ${ }^{[2]}$. 
The situational analysis can be cited amongst these competencies, that is the identification of health needs and priorities play an important role in the execution of actions aiming at the promotion of health ${ }^{[2]}$. Knowing why and how people adopted a certain lifestyle can be a good strategy to adequate more convincing measures in order to contribute to the change of a determined situation.

During the past thirty years, some epidemiologic studies have been performed aiming at the identification of risk behaviors that enable the appearance of non-communicable chronic diseases (NCCD) in the most diverse publics, including school ${ }^{[3]}$ and university students ${ }^{[4-9]}$. Although there is an ample literature on the topic, there is a lack of studies aimed at investigating these behaviors in nursing undergraduates of public universities in the state of Ceara, Brazil.

Thus, the present study is interested in carrying out a situational analysis of lifestyles related to the risk factors for NCCD with nursing undergraduates of a public university of Fortaleza, Ceara, Brazil.

Based on this analysis, the nurse, making use of his/her communication and leadership skills, should take over the role of a health professional educator enabled to encourage the empowerment and participation of this youth in planning interventions on risk components. For this reason, professional and youth together can draw up a viable action plan with the goal of improving the latter's health.

\section{Methods}

Cross-sectional study developed from December 2010 to June 2011 at a public university in the city of Fortaleza - CE by applying a questionnaire.

\subsection{Sample}

This study is part of a larger project whose main goal is to identify the prevalence of metabolic syndrome among the students of a public institution of higher education in the city of Fortaleza. For the sampling calculation of the larger study, a survey was carried out of every student enrolled in the institution's presence-based courses. After this survey and the application of the formula for infinite populations ${ }^{[10]}(\mathrm{P}=50 \%, \mathrm{Q}=50 \%$, absolute error of $8 \%$, relative of $4 \%), 660$ subjects were achieved. The sample was stratified through every knowledge area existing in the institution, and for convenience two courses of each were selected. Nursing and pharmacy courses were selected from the health area. According to the stratification, 92 subjects should be part of the health area, being 15 for the pharmacy course and 77 for the nursing course. As the present study refers only to students of the nursing course, the sample comprised 77 participants.

The following were established as inclusion criteria: be aged 18 years or older, be duly enrolled and be attending the selected course.

\subsection{Sociodemographic variables}

The sociodemographic variables consisted of gender, age, marital status, skin color, social status and the college term. The "Economic Classification Criteria of Brazil" ${ }^{[11]}$ were used for the classification of social status.

\subsection{Physical conditions and lifestyle}

The following were considered as risk factors for NCCD: physical conditions, weight excess, central obesity and lifestyles related to physical inactivity, smoking and alcohol consumption.

Weight excess was obtained through the calculation of the Body Mass Index (BMI) defined as the weight $(\mathrm{kg})$ and the square of height $(\mathrm{m})$ ratio. The classification occurred as per WHO ${ }^{[12]}$. The subjects with values $<25 \mathrm{~kg} / \mathrm{m}^{2}$ were considered eutrophic; those with values between 25.0 and $29.9 \mathrm{~kg} / \mathrm{m}^{2}$ were considered overweight; and obese those with $\mathrm{BMI} \geq 30 \mathrm{~kg} / \mathrm{m}^{2}$. 
For the BMI calculation, weight was measured with students barefooted, light clothed and without any accessories that could compromise the measurement accuracy. A $200 \mathrm{~kg}$-capacity electronic anthropometric scale for adults was used. Height was evaluated by an inelastic anthropometric tape fixed on a smooth wall. In order to ensure height accuracy, subjects were advised to stay erect and still, with hands flat on their thighs and head positioned at the Frankfurt plan.

Central obesity was defined according to the waist circumference (WC) measure by using an ineslatic metric tape placed on the student's skin on orthostatic position and erect in the medium point between the last rib and the iliac crest at the end of the expiratory movement. The following measures were adopted as normal reference values: $<102 \mathrm{~cm}$ for men and $<88$ cm for women ${ }^{[13,14]}$.

As for the physical inactivity, subjects were classified as active and sedentary ${ }^{[15]}$. With regard to smoking, students were classified as follows: daily smoker, occasional smoker, ex-smoker and non-smoker ${ }^{[16]}$. Alcohol consumption was classified in risk zones: $1,2,3$ and $4{ }^{[17,18]}$.

\subsection{Data analysis}

Data were processed with SPSS, version 17.0. Statistical measures (medium and standard deviation) were calculated for every quantitative variable, in addition to the inferential statistical analysis and the confidence intervals of 95\% (CI95\%).

As demanded, the project was submitted to the Ethics Committee on Human Beings Research of the Federal University of Ceara, where it obtained a favorable opinion.

\section{Results}

Table 1. Characterization of the nursing undergraduates according to sociodemographic and clinical variables. Fortaleza-CE, 2011

\begin{tabular}{|c|c|c|c|}
\hline Variables & No. & $\%$ & \\
\hline Age (years) & & & Average \pm DP \\
\hline $18-19$ & 16 & 20.8 & $21.6 \pm 2.7$ years \\
\hline $20-24$ & 52 & 67.5 & \\
\hline $25-35$ & 9 & 11.7 & \\
\hline \multicolumn{4}{|l|}{ Color (self-reported) } \\
\hline White & 37 & 48.1 & \\
\hline Black & 3 & 3.9 & \\
\hline Yellow & 5 & 6.5 & \\
\hline Brown & 32 & 41.5 & \\
\hline \multicolumn{4}{|l|}{ Marital Status } \\
\hline married/mutual consent union & 5 & 6.5 & \\
\hline Single & 72 & 93.5 & \\
\hline \multicolumn{4}{|l|}{ Social Status } \\
\hline A 2 & 11 & 14.5 & \\
\hline B & 37 & 48.6 & \\
\hline $\mathrm{C}$ & 21 & 27.6 & \\
\hline $\mathrm{D} / \mathrm{E}$ & 7 & 9.3 & \\
\hline \multicolumn{4}{|l|}{ Academic Term } \\
\hline $1^{\text {st }}$ year & 16 & 20.8 & \\
\hline $2^{\text {nd }}$ year & 21 & 27.2 & \\
\hline $3^{\text {rd }}$ year & 19 & 24.7 & \\
\hline $4^{\text {th }}$ year & 21 & 27.3 & \\
\hline
\end{tabular}


All of the subjects were females. While age varied from 18 to 35 with an average of $21.6 \pm 2.7$ years, monthly family income presented an average of 3,564.20 $\pm 2,117.70$ Reais (Brazilian currency). The population's characteristics regarding sociodemographic data and risk factors are displayed in the following tables.

From the data shown in table 1, the following results prevailed in the sample studied: female subjects between the ages of 20 and 24 years $(67.5 \%)$; white subjects $(48.1 \%)$; single subjects $(93.5 \%)$; subjects among social class B (48.6\%); and subjects in the 3 rd and 4 th years of college $(52.0 \%)$.

With respect to the physical conditions and lifestyles associated with NCCD, although most of the students had been classified as sedentary $(75.3 \%),(89.3 \%)$ presented adequate weight for height and the waist circumference values within the normal reference values (98.7\%). Besides, they stated being non-smokers $(94.8 \%)$ and having low risk for alcohol consumption (93.5\%) (see Table 2).

Table 2. Characterization of the nursing undergraduates according to physical conditions and lifestyles variables. Fortaleza-CE, 2011

\begin{tabular}{lll}
\hline Variables & No. & $\%$ \\
\hline Body Mass Index & & \\
Eutrophic & 67 & 89.3 \\
Overweight & 8 & 10.7 \\
Waist Circumference & & \\
$\leq 88 \mathrm{~cm}$ & 76 & 98.7 \\
$>88 \mathrm{~cm}$ & 1 & 1.3 \\
Physical Activity Practice & & \\
Active & 19 & 24.7 \\
Sedentary & 58 & 75.3 \\
Smoking & & \\
Smoker & 4 & 5.2 \\
Non-smoker & 73 & 94.8 \\
Alcohol Consumption & & \\
Low-risk standard & 72 & 93.5 \\
Medium-risk standard & 5 & 6.5 \\
\hline
\end{tabular}

\section{Discussion}

As mentioned, identifying health problems and inadequate lifestyles such as obesity, smoking, alcohol consumption and sedentarism can be of great importance for the survey of a community's health needs and priorities. In the present study carried out with nursing undergraduates, elevated prevalences of healthy lifestyles in relation to weight, central obesity, smoking and alcohol consumption were identified.

In regard to smoking, only four undergraduates (5.2\%) claimed to be smokers. Low smoking prevalences were also found in similar studies also performed with undergraduate health students ${ }^{[5-7]}$. In contrast, a higher smoking prevalence (27.7\%) was found in a study with undergraduate biological sciences students ${ }^{[8]}$.

In the present study, alcohol consumption even at lower risk standard and sedentarism were the most prevalent inadequate lifestyles. Elevated alcohol consumption prevalences ${ }^{[8,19]}$ and sedentarism ${ }^{[9,20]}$ were also highlighted in similar researches with young university students. The high percentage of sedentary and low-active students was similar to the results described by other authors ${ }^{[21,22]}$.

Although undergraduate health students are aware about the importance of practicing a physical activity on a regular basis as a protective factor against the appearance of NCCD, a high sedentarism prevalence is found among them. Maybe this 
high rate is directly related to the work hours demanded in health courses, which mostly require full-time commitment (morning and afternoon). This assumption can be confirmed in a study about the undergraduate health students' physical activity level in which, when asked about the "reason for not practicing a physical activity", most of them (66.7\%) claimed lack of time among other options ${ }^{[9]}$.

Despite being considered sedentary and as such constituting a decisive factor for weight gain, the present study's female undergraduates showed low prevalence of weight excess. Only 8 (10.7\%) of the participants were classified as overweight, none of them as obese. Furthermore, only one female undergraduate had waist circumference values above $88 \mathrm{~cm}$, while all the others were classified within the normal standards. This lower frequency of weight excess in the female gender was also described by other authors ${ }^{[23,24]}$.

However, it is worth noting that the low prevalences of weight excess found in this study may be related to the participants' socioeconomic status, once the women's desires to be thin are very common among the ones belonging to a higher social class $^{[25]}$.

In order to be a professional with abilities to act as a health promoter, the nurse should have knowledge, skill and attitude ${ }^{[2]}$. By having this situational analysis on hand, the nurse needs to prepare his/her knowledge to adapt it to individualized care and health education programs in order to increase the chances of people to exercise greater control over themselves and on the environment, so that they can choose the most favorable health options ${ }^{[26]}$.

It is necessary for the health education activities to integrate nursing care. Such activities include: learning and awareness of individuals, family and community, through adequate and participative techniques with instructions on behavior changes and adoption of healthy lifestyles. In this context, as understood, health education should be a pedagogical strategy based on knowledge exchange among health professionals and individuals regarding the increase of the individual and the collectivity's potentials which is an essential condition for change ${ }^{[27]}$.

When approaching healthy individuals, as it is in the case of the present study's participants, the goals of health education actions should promote knowledge and reflection to encourage the perception of risk, which in turn, contribute to the maintenance of healthy lifestyles ${ }^{[28]}$. From this aspect, the nurse should use his/her knowledge not only to use disease prevention policies, but also to encourage the health maintenance of the populations, in particular the youth considered healthy, as it is the case ${ }^{[2]}$.

Furthermore, to achieve best results, the nurse, as a health promoter, should identify partners within and outside the health sector in addition to empowering individuals. This initiative can either determine the success or improve the health promotion efforts ${ }^{[2]}$. Therefore, other health professionals should be involved in this process as the physical educator, the nutritionist and the physician. Teamwork is thus favored and everyone's work is facilitated.

\section{Conclusion and implications}

The use of the situational analysis as an essential competency allowed the identification of lifestyles and physical conditions in undergraduate nursing students of a public university with regard to their exposure to the risk of acquiring NCCD throughout their lives. As observed, the results of this analysis were useful not only to identify the undergraduate students' characteristics, but also to highlight their real health needs and priorities.

In general, the undergraduates taking part in this study presented healthy lifestyles, since the majority was non-smoker and had low risk of alcohol consumption. Also, adequate protective physical conditions were identified, as there was only one case of central obesity and eight of weight excess (overweight). On the other hand, sedentarism occurred in most of the undergraduates, therefore, being the priority health problem in the investigated students. 


\section{I mplications for nursing}

Based on the present context, one can realize that the nurse as a health promoter should encourage young people's participation in the elaboration of incentive strategies and maintenance of healthy lifestyle practices, as well as in planning interventions aimed at fighting against factors considered risky for NCCD. Thus, it is possible to draw up a viable action plan aimed not only at the imposition of prohibitive behavior that is full of rules, which only determine what should or should not be done, but instead with the goal of improving the health of these students.

\section{Study's limitations}

Two limitations were identified in this study. First, all of the participants belonged to the health area, which might have led the result to a greater occurrence of healthy lifestyles. In addition to this, the sample size was very little representative, with just 77 students.

\section{Recommendations}

The results of this study point to the need to adopt educational programs at the investigated institution that aim at health promotion and NCCD prevention, such as: implementation of physical activity at the investigated educational institution to reduce sedentarism; development of new similar researches with more representative samples that include other areas of knowledge; and the elaboration of other researches in order to identify the factors that might favor or interfere in the acquisition of a healthy lifestyle among students.

\section{Acknowledgement}

Special thanks to the Brazilian National Council of Scientific and Technological Development (CNPq) for providing financial support to the present study.

\section{Source(s) of support}

Brazilian National Council of Scientific and Technological Development (CNPq)

\section{Conflicting interest}

The authors declare that they have no conflict of interests

\section{References}

[1] World Health Organization. Ottawa Charter for Health Promotion. First International Conference on Health Promotion, Ottawa [Internet]. 1986. Available from: http://www.who.int/hpr/NPH/docs/ottawa_charter_hp.pdf

[2] Dempsey C, Battel-Kirk B, Barry MM. The CompHP Core Competencies Framework for Health Promotion Handbook. Health Promotion Research Centre. National University of Ireland Galway [Internet]. 2011. Available from: http://www.iuhpe.org/uploaded/CompHP_Competencies_Handbook.pdf

[3] Malta DC, Sardinha LMV, Mendes I, Barreto SM, Giatti L, Castro IRR, Moura L, Dias AJR, Crespo C. Prevalence of risk health behavior among adolescents:results from the 2009 National Adolescent School-based Health Survey (PENSE), Brazil, 2009. Ciênc. saúde coletiva Suppl. 2010; 15(2): 3009-3019.

[4] Moraes AS, Meira L, Freitas ICM. Risk factors for non-communicable diseases in nursing students from Ribeirão Preto-Brazil. Medicine, Ribeirão Preto. 2000; 33: 312-321.

[5] Santos KP, Rodrigues A, Reinaldo AMS. Nursing students' academic training and their perception of smoking. Rev. Eletr. En [Internet]. 2007; 9(2):432-442. Available from: http://www.fen.ufg.br/revista/v9/n2/v9n2a11.htm

[6] Cinelli AN, Silva EC, Mello LC, Silva MPM, Nunes RN, Ueda SY. Review of knowledge of smoking in students of $5^{\circ}$ half of graduate courses in nursing, physical education, physical therapy, and the psychology at unianchieta university. Revista Multidisciplinar da Saúde. 2010; year II(03): 47-61. 
[7] Petribú MMV, Cabral PC, Arruda IKG. Nutritional status, food consumption and cardiovascular risk: a study on university students. Rev. Nutr. 2009; 22(6): 837-846.

[8] Silva LVER, Malbergier A, Stempliuk VA, Andrade AG. Factors associated with drug and alcohol use among university students. Rev Saúde Pública. 2006; 40(2): 280-288. http://dx.doi.org/10.1590/S0034-89102006000200014

[9] Marcondelli P, Costa THM, Schmitz BAS. Physical activity level and food intake habits of university students from 3 to 5 semester in the health area. Rev. Nutr. 2008 Jan-Feb; 21(1): 39-47. http://dx.doi.org/10.1590/S1415-52732008000100005

[10] Arango HG. Biostatistics theoretical and computational. 2. ed. Rio de Janeiro: Guanabara Koogan. 2005.

[11] Brazilian Association of Research Enterprises. Economic Classification Criterion of Brazil [Internet]. Available from: http://www.abep.org/codigosguias/Criterio_Brasil_2008.pdf

[12] World Health Organization. Obesity, preventing and managing the global epidemic: report of a WHO consultation. WHO technical report series, Geneva. 2000.

[13] Smith C, Essop MP. Gender differences in metabolic risk factor prevalence in a South African student population. Cardiovasc J Afr. 2009; 20(3): 178-182. PMid:19575082

[14] Grundy SM, Cleeman JI, Daniels SR, Donato K, Eckel RH, Franklin BA et al. Diagnosis and management of the metabolic syndrome: an American Hearth Association/National Heart, Lung and Blood Institute Scientific Statement. Circulation. 2005; 112: 2735-2752. PMid:16157765 http://dx.doi.org/10.1161/CIRCULATIONAHA.105.169404

[15] Souza LJ, Giovane NC, Chalita FE. Prevalence of Obesity and Cardiovascular Risk Factors in Campos, Rio de Janeiro. Arq Bras Endocrinol Metab. 2003; 47(6): 669-676. http://dx.doi.org/10.1590/S0004-27302003000600008

[16] World Health Organization. Tabacco country profiles. End ed. Proccedings of the 12th World Conference on Tobacco or Health, Helsinki, Finland. 2003.

[17] Méndez EB. A Brazilian version of AUDIT (Alcohol use disorders identification test). Doctorate Thesis. Federal University of Pelotas, Pelotas-RS. 1999.

[18] Figlie NB, Pillon SC, Dunn J, Laranjeira R. The frequency of smoking and problem drinking among general hospital inpatients in Brazil 2013 using the AUDIT and Fagerström questionnaires. São Paulo Med J. 2000; 118(5): 139-143. PMid:11018847 http://dx.doi.org/10.1590/S1516-31802000000500005

[19] Pereira DL, Moraes M, Laat EF, Pilatti LA. Life quality, alcohol consumption and smoking: a comparative between the aspects of life style, alcohol and smoking consumption in Engineering and Physical Education students from Unicentro, Irati Campus - PR. Revista Científica JOPEF. 2011; 12(1): 27-40.

[20] Veras VS, Monteiro LZ, Landim CAP, Xavier ATF, Pinheiro MHNP, Montenegro RM. Survey on risk factors for chronic diseases in college students. Brazilian Journal in Health Promotion. 2007; 20(3): 168-172.

[21] Palma A, Abreu RA, Cunha CA. Risk behavior and vulnerability among physical education students. Rev Bras Epidemiol. 2007; 10(1): 117-126.

[22] Guedes DP, Guedes JERP, Barbosa DS, Oliveira JA. Levels of regular physical activity in adolescents. Rev Bras Méd Esporte. 2001; 7(6): 187-199.

[23] Vieira VCR, Priore SE, Ribeiro SMR, Franceschini SCC, Almeida LP. Socieconomic, nutritional and health profile of adolescents recently admitted to a Brazilian public university. Rev Nutr. 2002; 15(3): 273-282.

[24] Neumann AICP, Shirassu MM, Fisberg RM. Consumption of protective and promotive foods in cardiovascular diseases among public employees. Rev Nutr. 2006; 19(1): 19-28. http://dx.doi.org/10.1590/S1415-52732006000100002

[25] Magalhães VC, Mendonça GAS. Prevalence of overweight and obesity and associated factors among adolescents in the northeast and southeast regions of Brazil, 1996 to 1997. Cad Saúde Pública. 2003; 19(1): S129-S139. PMid:12886443

[26] Verdi M, Caponi S. Reflections about health promotion on a bioethics. Texto contexto - enferm. 2005; 14(1): 82-88.

[27] Cardim MG, Rangel DLO, Lobo MB, Pereira AL. Health education: nursing academics' theory and practice. R. de Pesq.: cuidado é fundamental. 2005; year 9(1/2): 57-64.

[28] Palmeira CS, Pereira A, Melo C. Nursing practice in the prevention of cardiovascular diseases. Revista Baiana de Enfermagem. 2004/2005; 19/20(1/2/3): 83-91. 